\title{
Identification and functional analysis of differentially expressed genes in poorly differentiated hepatocellular carcinoma using RNA-seq
}

\author{
Yi Huang ${ }^{1,2, *}$, Jianbo Pan ${ }^{3, *}$, Dunyan Chen ${ }^{1,2}$, Jiaying Zheng ${ }^{1,2}$, Funan Qiü ${ }^{1,4}$, Feng $\mathbf{L i}^{2,5}$, \\ Yanan $\mathbf{W u}^{1,2}$, Wenbing $\mathbf{W u}^{1,2}$, Xiaoli Huang ${ }^{1,2}$, Jiang Qian ${ }^{3,6}$ \\ ${ }^{1}$ Department of Clinical Laboratory, Fujian Provincial Hospital, Fuzhou, Fujian 350001, China \\ ${ }^{2}$ Provincial Clinical College, Fujian Medical University, Fuzhou, Fujian 350001, China \\ ${ }^{3}$ Department of Ophthalmology, Johns Hopkins School of Medicine, Baltimore, MD 21205, USA \\ ${ }^{4}$ Department of Hepatobiliary Surgery, Fujian Provincial Hospital, Fuzhou, Fujian 350001, China \\ ${ }^{5}$ Department of Pathology, Fujian Provincial Hospital, Fuzhou, Fujian 350001, China \\ ${ }^{6}$ The Sidney Kimmel Comprehensive Cancer Center, Johns Hopkins School of Medicine, Baltimore, MD 21205, USA \\ *These authors contributed equally to this work \\ Correspondence to: Yi Huang, email: hyi1971@126.com \\ Jiang Qian, email: jiang.qian@jhmi.edu \\ Keywords: hepatocellular carcinoma, poorly differentiated, transcriptome sequencing, differentially expressed genes, \\ carcinogenesis
}

Received: February 07, 2017

Accepted: March 12, 2017

Published: March 21, 2017

Copyright: Huang et al. This is an open-access article distributed under the terms of the Creative Commons Attribution License (CC-BY), which permits unrestricted use, distribution, and reproduction in any medium, provided the original author and source are credited.

\section{ABSTRACT}

Poorly differentiated (PD) hepatocellular carcinoma (HCC) has a worse prognosis compared to moderately differentiated (MD) and well differentiated (WD) HCC. We aimed to identify differentially expressed genes (DEGs) to explore the mechanism of PD HCC. Transcriptome sequencing was performed on tumor and adjacent nontumorous tissues of PD, MD and WD HCC patients ( 3 for each group). DEGs were thus identified and functionally analyzed. Further RT-PCR was performed to validate DEGs specific for PD HCC in 47 pairs of samples (15 for PD, 18 for MD, 14 for WD). A total of 681 PD DEGs were detected, including 368 up-regulated and 313 downregulated genes. Less DEGs were found for MD and especially for WD HCC. Through bioinformatics analysis, PD HCC DEGs were enriched in liver tissue and liver cancer cells, and in biological process and pathway including metabolism, cell cycle, translation and blood coagulation. Potential drugs and genetic perturbations were found to reverse the cancer condition. The RT-PCR results showed consistency with RNA-seq in the validation of 4 DEGs specific for PD HCC. This study detected and validated DEGs of PD HCC, which provides useful information on molecular mechanism of PD HCC for development of new biomarkers, therapeutic targets and drugs.

\section{INTRODUCTION}

As one of the most common malignancies worldwide, hepatocellular carcinoma (HCC) represents the second-leading cause of cancer deaths globally with 745,000 deaths per year [1]. The HCC were categorized into poorly-, moderately-, and well- differentiated types. Hepatic resection is currently the most optimal choice for $\mathrm{HCC}$ treatment. However, poorly differentiated $\mathrm{HCC}$ has a worse prognosis with high recurrence rate compared to other two types [2, 3]. In addition, it is hard to discriminate poorly differentiated HCC from other two types of HCC before treatment. The lack of good diagnostic markers and therapeutic targets has rendered HCC a major challenge.

Recently, high-throughput technologies like RNA sequencing make it possible and easy to illustrate the transcriptome characteristics of cancers including HCC [4]. Some potential biomarkers for HCC were identified using transcriptome sequencing e.g. SERPINA11 whose expression is correlated with pathology stages lack documented expression profiles in liver cancer [5]. Some signaling pathways like cell cycle were also involved 
via analysis of transcriptome sequencing data [6]. Those studies show a great promise of exploring the molecular basis of HCC.

In this study, we performed transcriptome sequencing for patients with poorly differentiated (PD), moderately differentiated (MD) and well differentiated (WD) HCC. 3 patients diagnosed as HCC of each grades were recruited, respectively. Differentially expressed genes (DEGs) were identified through analysis of transcriptome sequencing data. DEGs were then subjected to gene set enrichment analysis. Furthermore, RT-PCR was performed to validate potential biomarkers in 15 pairs of poorly differentiated tumor and adjacent non-tumorous samples. Our investigation may provide new clues on the molecular event responsible for the progression of HCC and potential biomarkers and therapeutic targets for diagnosis and treatment of $\mathrm{HCC}$ patients.

\section{RESULTS}

\section{Overview of transcriptome sequencing statistics}

Pair-end second-generation transcriptome sequencing was performed in $9 \mathrm{HCC}$ patients. Sample characteristics were shown in Table 1. An average of 35,772,695 pair-end 125 bp clean reads was generated (Table 2). The average mapping rate was $93.17 \%$, resulting an average coverage of depth of $32 \times$ (Table 2). Expression levels of more than 25,200 genes were calculated using Tophat/Cufflinks (Supplementary Table 1). The heatmap of all expressed genes were drawn in Figure 1, which showed a big group of differentially expressed genes (DEGs) between tumor and adjacent non-tumorous samples of poorly differentiated HCC.

\section{Identification of DEGs between tumor and adjacent non-tumor tissues}

We next detected DEGs between tumor and adjacent non-tumorous samples of poorly differentiated, moderately differentiated and well differentiated HCC. Through paired- $T$ test analysis $(P$ value $<0.05$, Fold change $>2)$, a total of 1020 DEGs were detected including 372 up-regulated genes (313, 47 and 12 for poorly-, moderately- and well-differentiated HCC, respectively) and 648 down-regulated genes (368, 249 and 31 for poorly-, moderately- and well-differentiated HCC, respectively) (Figure 2A; Supplementary Table 2). Only 1 down-regulated gene (CD44) was overlapped in all 3 grades. Top 20 up-regulated genes and Top 20 down-regulated genes of poorly differentiated HCC were shown in Table 3 and Table 4, respectively.

\section{Significantly enriched functions for DEGs of poorly differentiated $\mathrm{HCC}$}

DEGs of poorly differentiated $\mathrm{HCC}$ were subjected to functional enrichment analyses to illustrate their biological function characteristics using Enrichr tool [7]. The top enriched terms for categories were shown in Figure 2B $(P$ value $<0.1)$. From Human Gene Atlas and Cancer Cell Line Encyclopedia, those DEGs were enriched in liver tissue and various liver cancer cells. The enriched biological process and pathway included metabolism, cell cycle, translation and blood coagulation. The DEGs tended to lie in mitochondrial, chromosome and ribosome. From the ENCODE TF ChIP-seq data, 5 transcription factors in liver cancer cell HEPG2 were enriched to regulate the poorly differentiated DEGs.

\section{Potential perturbations for reverse of abnormal gene expression change of poorly differentiated $\mathrm{HCC}$}

LINCS is a collection of signatures of gene expression for a broad range of conditions such as drug treatment, ligand treatment, gene knockdown, and gene over-expression in many different types of human cells [8]. We inputted the up-regulated genes and down-regulated genes into lincscloud to find perturbations that had opposite gene expression change with differentiated HCC. Top 12 perturbations with high negative connectivity scores (Figure 2C), which included 4 compounds, 7 knockdown genes and 1 over-expression gene.

\section{Comparison of tumor tissues between PD HCC and MD\&WD HCC}

Besides DEGs between tumor and adjacent nontumorous samples, we compared tumor tissues between PD HCC and MD\&WD HCC. As a result, 725 differentially expressed genes were identified (Supplementary Table 2); among them, 209 were identified as DEGs when comparing tumor and adjacent non-tumorous samples (Figure 2D). Gene ontology enrichment analysis was also done based on this 725gene list. Similarly, these genes were enriched in organelle fission, mitotic nuclear division, positive regulation of cell cycle phase transition and serine family amino acid catabolic process.

\section{Validation of DEGs specific for poorly differentiated HCC by RT-PCR}

4 DEGs specific for poorly differentiated HCC as well as related with cell cycle or proliferation were validated by RT-PCR. In the discovery phase, the expressions of NOVA1, NSMCE2 and KIAA0196 were significantly up-regulated, while expression of AQP9 was significantly down-regulated in poorly differentiated samples, as compared with that in adjacent non-tumorous samples, moderately differentiated samples and well differentiated samples $(P<0.05)$ (Table 5). RT-PCR results showed that all these 4 genes were successfully validated (Figure 3), and the dysregulation trend matched with those observed in the RNA-seq data. 
Table 1: Detailed characteristics of the patients

\begin{tabular}{|c|c|c|c|c|c|c|c|c|c|}
\hline Patient & Age & Gender & Hepatitis & $\begin{array}{c}\text { Serum AFP } \\
\text { level }(\mathrm{ng} / \mathrm{mL})\end{array}$ & Metastasis & $\begin{array}{c}\text { Glisson capsule } \\
\text { invasion }\end{array}$ & $\begin{array}{c}\text { Tumor } \\
\text { size }(\mathbf{m m})\end{array}$ & $\begin{array}{c}\text { Differentiation } \\
\text { Grade }\end{array}$ & $\begin{array}{c}\text { Multiple liver } \\
\text { nodules }\end{array}$ \\
\hline$P 1$ & 59 & $M$ & $H B V$ & 670.1 & No & - & 35 & Poorly & - \\
\hline$P 2$ & 50 & $M$ & $H B V$ & 12483 & No & + & 50 & Poorly & - \\
\hline P3 & 37 & $M$ & $H B V$ & 4.47 & No & + & 41 & Poorly & - \\
\hline M1 & 59 & $M$ & $H B V$ & 3.73 & No & - & 6 & moderately & - \\
\hline M2 & 69 & $M$ & $H B V$ & 6.9 & No & + & 160 & moderately & synchronous \\
\hline M3 & 61 & $M$ & $N B N C$ & 1.11 & No & + & 80 & moderately & - \\
\hline$W 1$ & 62 & $M$ & $H B V$ & 266.5 & No & + & 32 & Well & - \\
\hline$W 2$ & 76 & $M$ & $\mathrm{HCV}$ & 5.84 & No & + & 70 & Well & - \\
\hline$W 3$ & 19 & $F$ & $N B N C$ & 2.85 & No & - & 29 & Well & - \\
\hline $\mathrm{P} 4$ & 48 & M & NBNC & 55.1 & Yes & + & 180 & Poorly & - \\
\hline P5 & 41 & M & HBV & 4.7 & Yes & + & 50 & Poorly & - \\
\hline P6 & 64 & M & $\mathrm{HBV}$ & 244.6 & Yes & + & 65 & Poorly & synchronous \\
\hline P7 & 50 & M & $\mathrm{HBV}$ & 3.03 & Yes & + & 55 & Poorly & synchronous \\
\hline P8 & 47 & M & HBV & 62.47 & Yes & + & 105 & Poorly & - \\
\hline P9 & 64 & M & HBV & 36541 & Yes & + & 140 & Poorly & - \\
\hline P10 & 52 & M & HBV & 2100 & Yes & - & 35 & Poorly & - \\
\hline P11 & 52 & M & NBNC & 5.3 & No & + & 65 & Poorly & - \\
\hline $\mathrm{P} 12$ & 37 & M & $\mathrm{HBV}$ & 1810 & No & - & 55 & Poorly & - \\
\hline P13 & 48 & M & $\mathrm{HBV}$ & 2.07 & No & - & 35 & Poorly & - \\
\hline P14 & 52 & $\mathrm{~F}$ & NBNC & 2.45 & No & + & 22 & Poorly & - \\
\hline P15 & 58 & M & HBV & 6.52 & Yes & + & 58 & Poorly & synchronous \\
\hline M4 & 63 & M & HBV & 2975 & No & + & 70 & moderately & synchronous \\
\hline M5 & 47 & M & HBV & 5375 & Yes & + & 130 & moderately & - \\
\hline M6 & 72 & M & HBV & 303.8 & No & + & 40 & moderately & synchronous \\
\hline M7 & 66 & M & HBV & 60500 & No & + & 50 & moderately & - \\
\hline M8 & 59 & M & NBNC & 54.84 & No & + & 26 & moderately & - \\
\hline M9 & 67 & M & HBV & 321.1 & No & + & 55 & moderately & synchronous \\
\hline M10 & 71 & M & HBV & 4606 & Yes & + & 12 & moderately & - \\
\hline M11 & 18 & $\mathrm{~F}$ & HBV & 37979 & No & + & 70 & moderately & - \\
\hline M12 & 45 & M & HBV & 6528 & No & + & 60 & moderately & synchronous \\
\hline M13 & 61 & M & $\mathrm{HBV}$ & 1.9 & No & + & 30 & moderately & - \\
\hline M14 & 52 & M & $\mathrm{HBV}$ & 26.53 & No & + & 20 & moderately & - \\
\hline M15 & 58 & $\mathrm{~F}$ & $\mathrm{HBV}$ & 2.55 & Yes & + & 55 & moderately & synchronous \\
\hline M16 & 42 & M & HBV & 3.38 & No & + & 20 & moderately & synchronous \\
\hline M17 & 64 & M & $\mathrm{HBV}$ & 774.2 & No & + & 10 & moderately & - \\
\hline M18 & 54 & $\mathrm{~F}$ & NBNC & 23784 & No & + & 22 & moderately & - \\
\hline W4 & 72 & M & HBV & 11.10 & No & + & 20 & Well & - \\
\hline W5 & 55 & M & HBV & 1.82 & No & + & 34 & Well & - \\
\hline W6 & 76 & M & NBNC & 2.1 & No & + & 34 & Well & - \\
\hline W7 & 67 & M & NBNC & 3.30 & No & - & 18 & Well & - \\
\hline W8 & 50 & M & HBV & 260.9 & No & - & 25 & Well & - \\
\hline W9 & 71 & M & HBV & 11.65 & No & + & 35 & Well & - \\
\hline W10 & 74 & M & NBNC & 5.9 & No & + & 30 & Well & - \\
\hline W11 & 39 & M & $\mathrm{HBV}$ & 8.10 & Yes & + & 22 & Well & synchronous \\
\hline W12 & 63 & M & HBV & 208 & No & + & 40 & Well & - \\
\hline W13 & 48 & M & NBNC & 3.07 & No & - & 33 & Well & - \\
\hline W14 & 66 & M & $\mathrm{HBV}$ & 82.81 & No & + & 34 & Well & - \\
\hline
\end{tabular}

Note: The nine samples used for sequencing are labeled in bold and italic. 
Table 2: Summary statistics of the transcriptome sequencing

\begin{tabular}{ccccccccc}
\hline Patient & $\begin{array}{c}\text { Differentiation } \\
\text { grade }\end{array}$ & $\begin{array}{c}\text { Sample } \\
\text { Type }\end{array}$ & $\begin{array}{c}\text { Total } \\
\text { reads }\end{array}$ & $\begin{array}{c}\text { Mapped } \\
\text { reads }\end{array}$ & $\begin{array}{c}\text { Total base } \\
\text { (bp) }\end{array}$ & $\begin{array}{c}\text { Mapped } \\
\text { base (bp) }\end{array}$ & $\begin{array}{c}\text { Mappping } \\
\text { ratio }\end{array}$ & $\begin{array}{c}\text { Coverage } \\
\text { (X) }\end{array}$ \\
\hline \multirow{2}{*}{ P1 } & \multirow{2}{*}{ Poorly } & $\mathrm{T}$ & $35,930,408$ & $33,819,287$ & $4,491,301,000$ & $4,227,410,875$ & $94.12 \%$ & 33 \\
& & $\mathrm{~N}$ & $34,902,228$ & $32,863,973$ & $4,362,778,500$ & $4,107,996,625$ & $94.16 \%$ & 32 \\
P2 & Poorly & $\mathrm{T}$ & $35,315,378$ & $33,125,921$ & $4,414,422,250$ & $4,140,740,125$ & $93.80 \%$ & 32 \\
& & $\mathrm{~N}$ & $34,383,802$ & $32,279,443$ & $4,297,975,250$ & $4,034,930,375$ & $93.88 \%$ & 31 \\
P3 & \multirow{2}{*}{ Poorly } & $\mathrm{T}$ & $35,532,658$ & $33,258,212$ & $4,441,582,250$ & $4,157,276,500$ & $93.60 \%$ & 32 \\
& & $\mathrm{~N}$ & $34,537,914$ & $32,152,860$ & $4,317,239,250$ & $4,019,107,500$ & $93.09 \%$ & 31 \\
M1 & \multirow{2}{*}{ Moderately } & $\mathrm{T}$ & $34,566,526$ & $32,670,216$ & $4,320,815,750$ & $4,083,777,000$ & $94.51 \%$ & 31 \\
& & $\mathrm{~N}$ & $35,384,486$ & $33,407,169$ & $4,423,060,750$ & $4,175,896,125$ & $94.41 \%$ & 32 \\
M2 & \multirow{2}{*}{ Moderately } & $\mathrm{T}$ & $34,564,642$ & $32,385,294$ & $4,320,580,250$ & $4,048,161,750$ & $93.69 \%$ & 31 \\
& & $\mathrm{~N}$ & $34,771,048$ & $32,792,475$ & $4,346,381,000$ & $4,099,059,375$ & $94.31 \%$ & 32 \\
M3 & \multirow{2}{*}{ Moderately } & $\mathrm{T}$ & $35,371,920$ & $32,571,695$ & $4,421,490,000$ & $4,071,461,875$ & $92.08 \%$ & 31 \\
& & $\mathrm{~N}$ & $35,959,532$ & $32,990,753$ & $4,494,941,500$ & $4,123,844,125$ & $91.74 \%$ & 32 \\
W1 & \multirow{2}{*}{ Well } & $\mathrm{T}$ & $34,762,386$ & $32,701,011$ & $4,345,298,250$ & $4,087,626,375$ & $94.07 \%$ & 31 \\
& & $\mathrm{~N}$ & $35,314,918$ & $33,021,170$ & $4,414,364,750$ & $4,127,646,250$ & $93.50 \%$ & 32 \\
W2 & \multirow{2}{*}{ Well } & $\mathrm{T}$ & $35,610,444$ & $32,509,118$ & $4,451,305,500$ & $4,063,639,750$ & $91.29 \%$ & 31 \\
& & $\mathrm{~N}$ & $34,637,398$ & $31,280,461$ & $4,329,674,750$ & $3,910,057,625$ & $90.31 \%$ & 30 \\
W3 & \multirow{2}{*}{ Well } & $\mathrm{T}$ & $42,279,434$ & $39,097,967$ & $5,284,929,250$ & $4,887,245,875$ & $92.50 \%$ & 38 \\
& & $\mathrm{~N}$ & $40,083,384$ & $36,852,292$ & $5,010,423,000$ & $4,606,536,500$ & $91.90 \%$ & 35 \\
Average & & & $35,772,695$ & $33,321,073$ & $4,471,586,847$ & $4,165,134,146$ & $93.17 \%$ & 32 \\
\hline
\end{tabular}

Note: $\mathrm{T}$ and $\mathrm{N}$ represent tumor and adjacent non-tumor tissue, respectively.

\section{DISCUSSION}

We have applied the transcriptome sequencing approach to illustrate the gene expression characteristics of poorly differentiated HCC. The number of DEGs for poorly differentiated HCC is significantly bigger than that of other two stages. Those DEGs are enriched in liver tissue and cells, which is easily understood. Pathway analysis showed that two pathways, cell cycle and complement and coagulation cascades, were overrepresented with DEGs. Deregulation of the cell cycle pathway is expected since uncontrolled cell division is the major character of cancer cells. As for the complement and coagulation cascades pathway, consistent with our results, both gene expression [9] and proteomics [10] analysis have shown that this pathway is related to the pathogenesis of HCC. Some transcription factors were found to regulate the DEGs. For example, HNF4- $\alpha$ could represent a central regulator of gene transcription in hepatocytes, and a strong candidate to be involved in liver cancer cell development [11]. In addition, we also compared tumor tissues between PD HCC and MD\&WD HCC. And similarly, the differentially expressed genes are enriched in the process of cell cycle and division.

After query of the poorly differentiated $\mathrm{HCC}$ signature in the LINCS server in our study, some compounds, knockdown genes and overexpression genes were found to have strong negative connections with the signature. PI-103 is a potent ATP-competitive dual inhibitor of phosphatidylinositol 3-kinase (PI3K) and mTOR (mammalian target of rapamycin). The combination of PI-103 and sorafenib was found to inhibit hepatocellular carcinoma cell proliferation by blocking Ras/Raf/MAPK and PI3K/AKT/mTOR pathways [12]. MK-2206 is an oral selective allosteric inhibitor of Akt that targets all three isoforms of human Akt (Akt-1, Akt-2 and Akt-3). MK2206 was found to inhibit hepatocellular carcinoma cellular proliferation via induction of apoptosis and cell cycle arrest [13]. Among 8 genetic perturbations, 5 genes are enriched in pathways in cancer or PI3KAkt signaling pathway $(\mathrm{p}<0.001)$. Myc proto-oncogene protein (MYC) as a transcription factor can activate the transcription of growth-related genes. HCC is frequently associated with overexpression of MYC. In this study, MYC is up-regulated in the poorly differentiated HCC. Knockdown of oncogenic KRAS was found to suppress tumor growth in non-small cell lung cancers [14]. As mentioned, AKT2 is the target of MK2206, knockdown and inhibition of AKT2 may both help to reverse HCC. Overexpression of cyclin dependent kinase inhibitor 1B (CDKN1B) has the reverse effect in our study. CDKN1B binds to and prevents the activation of cyclin 
complexes, and thus controls the cell cycle progression at G1 [15]. All those perturbations may be the potential therapies or targets for treatment of HCC. In the validation cohort, further RT-PCR was performed to validate 4 DEGs specific for poorly differentiated HCC, of which NOVA1, NSMCE2 and KIAA0196 were significantly up-regulated, while AQP9 was significantly downregulated in poorly differentiated samples, as compared with that in 9 adjacent non-tumor samples, 3 moderately differentiated samples and 3 well differentiated samples. The RT-PCR results showed consistency with RNA-seq. Interestingly, these DEGs were closely related with cell cycle or proliferation. High expression of NOVA1 was found correlated with poor survival rate and increased recurrence rate in HCC [16]. NSMCE2 was required for G1-S transition in breast cancer cells and manipulation of NSMCE2-mediated sumoylation may alter the growth rates of breast cancer cells [17]. KIAA0196, involving in meiosis-related spindle assembly [18], has been showed increased expression in clinical prostate carcinomas and also amplified in 30-40\% of xenografts and hormonerefractory tumors [19]. However, AQP9 has been found to be down-regulated in hepatocellular carcinoma and its over-expression suppresses hepatoma cell invasion through inhibiting epithelial-to-mesenchymal transition [20]. In conclusion, this study explored the molecular mechanism of hepatocarcinogenesis through assessment of RNA seq data of HCC and validation of 4 DEGs specific for poorly differentiated HCC in an independent cohort. It provides useful information on the transcriptomic landscape as well as a mechanistic overview of HCC. Our findings offer novel insights and useful support in biomarker development and suggest new potential targets in poorly differentiated HCC characterization.

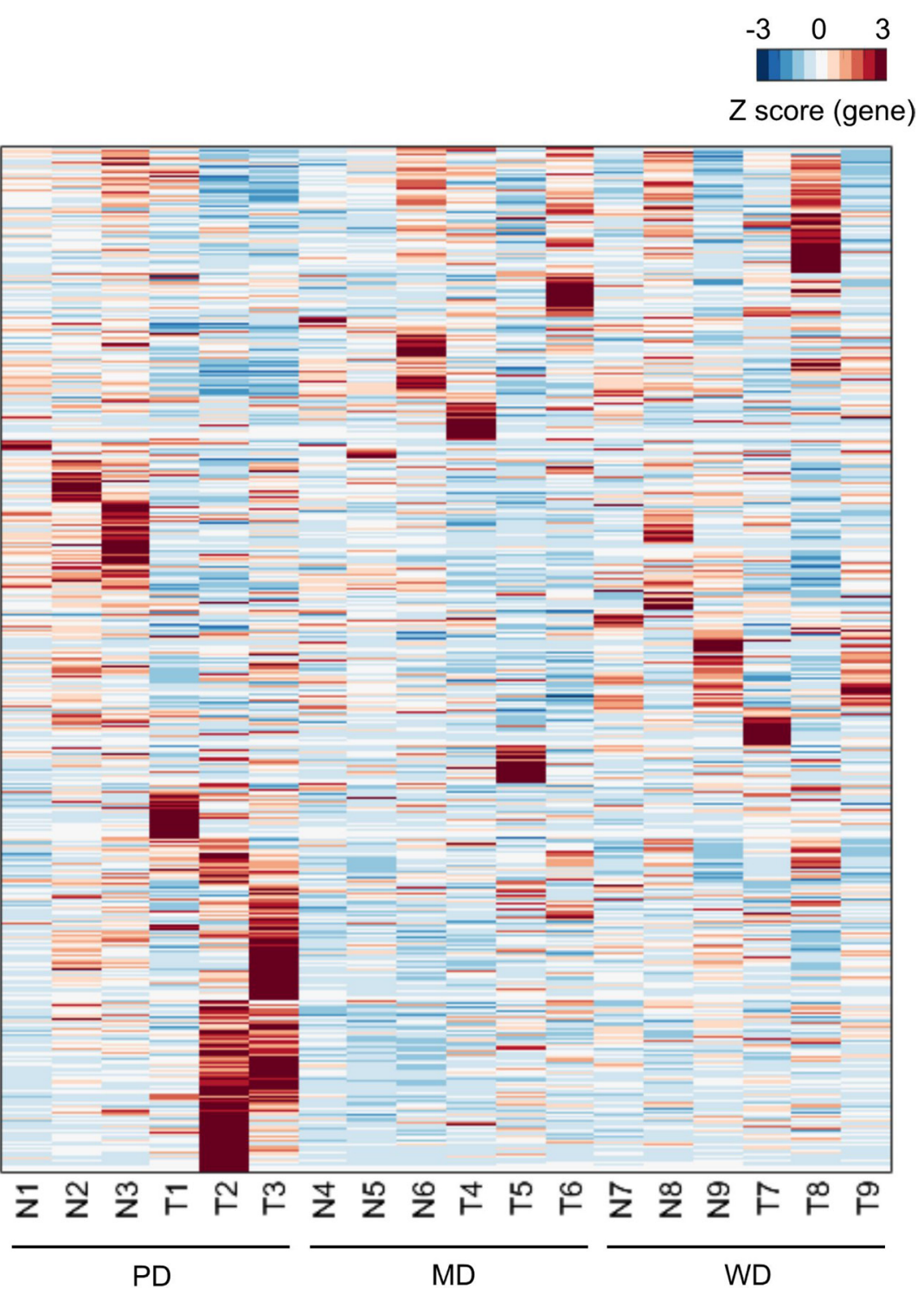

Figure 1: Heatmap of expressed genes. For the sample labels, $\mathrm{N}$ and $\mathrm{T}$ represented matched adjacent non-tumor tissue specimens and tumor tissue specimens respectively. Each row represented of $\mathrm{Z}$ scores of genes across different samples. 
Table 3: Top 20 up-regulated genes of poorly differentiated HCC

\begin{tabular}{|c|c|c|c|c|c|c|c|c|c|c|c|}
\hline Entrez_ID & $\begin{array}{c}\text { Gene } \\
\text { Symbol }\end{array}$ & N1 & N2 & $\mathbf{N 3}$ & T1 & $\mathbf{T} 2$ & T3 & $\begin{array}{c}\text { Group mean } \\
\text { _exp_N }\end{array}$ & $\begin{array}{c}\text { Group mean } \\
\text { _exp_T }\end{array}$ & $\begin{array}{c}\text { Group } \\
\_\log 2 \mathrm{FC}\end{array}$ & $\begin{array}{c}\text { Group ttest } \\
p \text { value }\end{array}$ \\
\hline 10130 & PDIA6 & 116.76 & 123.98 & 126.57 & 255.14 & 260.71 & 263.04 & 122.44 & 259.63 & 1.08 & $1.90 \mathrm{E}-05$ \\
\hline 578 & BAK1 & 6.41 & 5.00 & 9.99 & 20.24 & 18.51 & 23.98 & 7.14 & 20.91 & 1.43 & $1.03 \mathrm{E}-04$ \\
\hline 1650 & DDOST & 53.21 & 72.67 & 59.72 & 115.80 & 139.67 & 121.44 & 61.87 & 125.64 & 1.01 & $6.57 \mathrm{E}-04$ \\
\hline 2786 & GNG4 & 0.04 & 0.02 & 0.23 & 1.84 & 1.90 & 2.21 & 0.10 & 1.98 & 1.45 & 7.97E-04 \\
\hline 84933 & C8orf76 & 6.03 & 5.11 & 6.90 & 24.33 & 21.27 & 23.79 & 6.01 & 23.13 & 1.78 & $1.35 \mathrm{E}-03$ \\
\hline 22996 & TTC39A & 0.04 & 0.29 & 0.46 & 2.38 & 2.35 & 2.73 & 0.26 & 2.49 & 1.46 & $1.46 \mathrm{E}-03$ \\
\hline 5691 & PSMB3 & 119.36 & 132.67 & 145.10 & 301.66 & 342.81 & 347.47 & 132.37 & 330.64 & 1.31 & $1.74 \mathrm{E}-03$ \\
\hline 54522 & ANKRD16 & 1.87 & 2.67 & 2.10 & 6.20 & 7.28 & 7.16 & 2.21 & 6.88 & 1.29 & $2.04 \mathrm{E}-03$ \\
\hline 28998 & MRPL13 & 13.72 & 14.12 & 18.44 & 69.51 & 61.37 & 73.26 & 15.43 & 68.05 & 2.07 & $2.62 \mathrm{E}-03$ \\
\hline 50854 & C6orf48 & 28.97 & 70.17 & 66.97 & 111.29 & 140.99 & 150.56 & 55.37 & 134.28 & 1.26 & $2.64 \mathrm{E}-03$ \\
\hline 3094 & HINT1 & 270.52 & 305.61 & 289.43 & 605.26 & 590.80 & 625.23 & 288.52 & 607.10 & 1.07 & $2.74 \mathrm{E}-03$ \\
\hline 4738 & NEDD8 & 131.06 & 138.11 & 152.30 & 291.78 & 329.80 & 338.89 & 140.49 & 320.16 & 1.18 & $2.84 \mathrm{E}-03$ \\
\hline 57538 & ALPK3 & 0.47 & 1.81 & 1.41 & 3.16 & 4.41 & 3.61 & 1.23 & 3.73 & 1.08 & $3.65 \mathrm{E}-03$ \\
\hline 65244 & SPATS2 & 2.33 & 3.32 & 3.91 & 6.11 & 7.99 & 8.07 & 3.18 & 7.39 & 1.00 & $3.73 \mathrm{E}-03$ \\
\hline 8624 & PSMG1 & 15.75 & 16.67 & 25.69 & 37.42 & 39.74 & 44.17 & 19.37 & 40.44 & 1.02 & 4.12E-03 \\
\hline 8836 & GGH & 61.61 & 26.09 & 42.65 & 124.45 & 87.68 & 117.67 & 43.45 & 109.93 & 1.32 & 4.12E-03 \\
\hline 23640 & HSPBP1 & 7.35 & 11.32 & 9.61 & 19.05 & 25.08 & 24.27 & 9.42 & 22.80 & 1.19 & $4.27 \mathrm{E}-03$ \\
\hline 79075 & DSCC1 & 0.34 & 0.51 & 1.13 & 4.16 & 4.12 & 4.17 & 0.66 & 4.15 & 1.63 & $4.36 \mathrm{E}-03$ \\
\hline 5591 & PRKDC & 5.80 & 5.46 & 7.02 & 17.28 & 15.77 & 16.09 & 6.09 & 16.38 & 1.29 & $4.50 \mathrm{E}-03$ \\
\hline 84701 & COX4I2 & 0.22 & 1.13 & 0.23 & 3.16 & 4.83 & 3.73 & 0.53 & 3.91 & 1.69 & $4.56 \mathrm{E}-03$ \\
\hline
\end{tabular}

Note: T1, T2, T3 represent tumor tissue of P1, P2, P3 with poorly differentiated HCC, respectively; N1, N2, N3 represent adjacent non-tumor tissue of P1, P2, P3 with poorly differentiated HCC, respectively.

Table 4: Top 20 down-regulated genes of poorly differentiated HCC

\begin{tabular}{|c|c|c|c|c|c|c|c|c|c|c|c|}
\hline Entrez_ID & $\begin{array}{c}\text { Gene } \\
\text { Symbol }\end{array}$ & N1 & N2 & N3 & T1 & $\mathbf{T} 2$ & T3 & $\begin{array}{l}\text { Group } \\
\text { mean } \\
\text { exp_N }\end{array}$ & $\begin{array}{c}\text { Group } \\
\text { mean } \\
\text { exp_T }\end{array}$ & $\begin{array}{c}\text { Group } \\
-\log 2 \mathrm{FC}\end{array}$ & $\begin{array}{c}\text { Group ttest } \\
p \text { value }\end{array}$ \\
\hline 83854 & ANGPTL6 & 25.01 & 28.16 & 28.36 & 4.67 & 8.61 & 8.62 & 27.18 & 7.30 & -1.76 & $1.44 \mathrm{E}-04$ \\
\hline 2706 & GJB2 & 14.85 & 15.50 & 12.98 & 2.92 & 3.18 & 1.25 & 14.44 & 2.45 & -2.16 & $2.00 \mathrm{E}-04$ \\
\hline 23002 & DAAM1 & 5.54 & 5.70 & 6.63 & 1.39 & 1.70 & 2.41 & 5.96 & 1.83 & -1.30 & $2.23 \mathrm{E}-04$ \\
\hline 8671 & SLC4A4 & 10.64 & 9.24 & 9.18 & 2.04 & 1.21 & 1.14 & 9.68 & 1.46 & -2.12 & $5.10 \mathrm{E}-04$ \\
\hline 389643 & NUGGC & 8.92 & 9.30 & 8.32 & 1.61 & 2.46 & 1.52 & 8.85 & 1.86 & -1.78 & $5.44 \mathrm{E}-04$ \\
\hline 80824 & DUSP16 & 18.19 & 15.58 & 14.62 & 8.60 & 6.06 & 5.75 & 16.13 & 6.80 & -1.13 & $5.97 \mathrm{E}-04$ \\
\hline 1756 & DMD & 19.00 & 20.67 & 22.49 & 1.15 & 4.00 & 4.22 & 20.72 & 3.12 & -2.40 & $7.46 \mathrm{E}-04$ \\
\hline 2244 & FGB & 4822.00 & 2846.01 & 2754.51 & 2475.77 & 484.91 & 192.48 & 3474.17 & 1051.05 & -1.72 & 8.24E-04 \\
\hline 56907 & SPIRE1 & 3.97 & 5.48 & 6.04 & 0.96 & 2.07 & 2.81 & 5.17 & 1.95 & -1.06 & $1.29 \mathrm{E}-03$ \\
\hline 283537 & SLC46A3 & 39.62 & 40.22 & 43.44 & 4.31 & 1.39 & 8.81 & 41.09 & 4.84 & -2.85 & $1.29 \mathrm{E}-03$ \\
\hline 132671 & SPATA18 & 2.87 & 2.41 & 2.67 & 0.12 & 0.02 & 0.20 & 2.65 & 0.11 & -1.71 & $1.81 \mathrm{E}-03$ \\
\hline 1003 & CDH5 & 14.79 & 13.86 & 23.11 & 2.30 & 1.73 & 9.11 & 17.25 & 4.38 & -1.76 & $1.97 \mathrm{E}-03$ \\
\hline 4051 & CYP4F3 & 116.69 & 77.42 & 71.59 & 57.44 & 8.09 & 7.12 & 88.57 & 24.21 & -1.83 & $2.04 \mathrm{E}-03$ \\
\hline 9953 & HS3ST3B1 & 5.67 & 5.24 & 4.49 & 0.63 & 0.47 & 0.18 & 5.13 & 0.43 & -2.10 & $2.05 \mathrm{E}-03$ \\
\hline 10894 & LYVE1 & 43.68 & 40.34 & 38.97 & 0.56 & 3.11 & 0.76 & 41.00 & 1.48 & -4.08 & $2.12 \mathrm{E}-03$ \\
\hline 57188 & ADAMTSL3 & 5.57 & 4.39 & 4.54 & 1.40 & 0.08 & 0.87 & 4.83 & 0.78 & -1.71 & $2.25 \mathrm{E}-03$ \\
\hline 152926 & PPM1K & 3.52 & 3.35 & 4.35 & 0.93 & 0.81 & 1.39 & 3.74 & 1.04 & -1.21 & $2.27 \mathrm{E}-03$ \\
\hline 8658 & TNKS & 6.36 & 5.58 & 6.40 & 2.33 & 2.03 & 2.20 & 6.11 & 2.19 & -1.16 & $2.44 \mathrm{E}-03$ \\
\hline 116519 & APOA5 & 208.64 & 134.96 & 119.75 & 88.24 & 9.53 & 14.19 & 154.45 & 37.32 & -2.02 & $2.58 \mathrm{E}-03$ \\
\hline 90417 & KNSTRN & 2.17 & 3.28 & 4.17 & 7.96 & 6.80 & 8.81 & 3.21 & 7.85 & 1.07 & $1.94 \mathrm{E}-02$ \\
\hline
\end{tabular}

Note: T1, T2, T3 represent tumor tissue of P1, P2, P3 with poorly differentiated HCC, respectively; N1, N2, N3 represent adjacent non-tumor tissue of P1, P2, P3 with poorly differentiated HCC, respectively. 


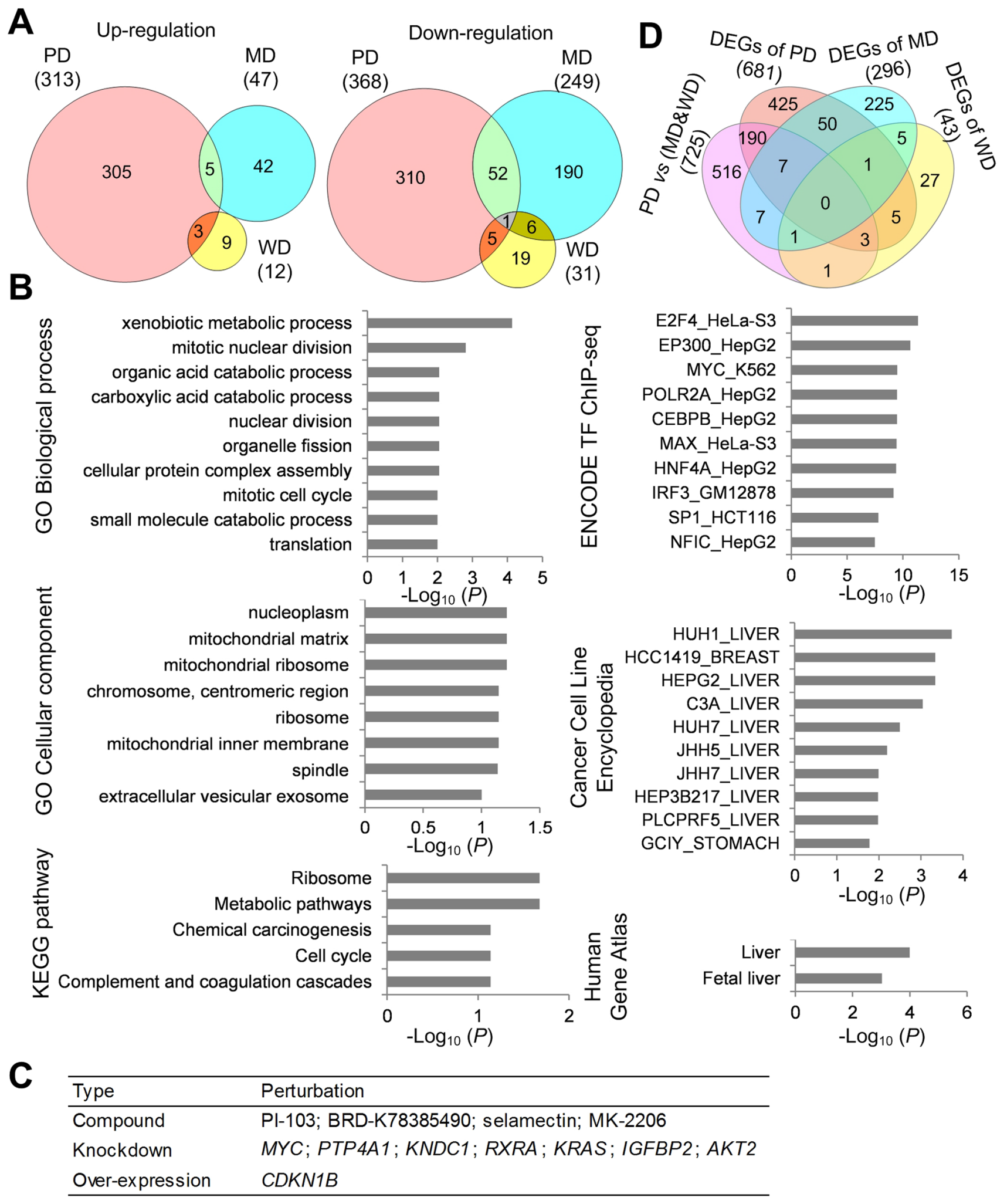

Figure 2: Functional characterization of DEGs. (A) Venn diagram of DEGs between poorly differentiated (PD), moderately differentiated (MD) and well differentiated (WD) HCC. (B) Functional enrichment analysis of DEGs of poorly differentiated HCC. (C) Top 12 perturbations with high negative connectivity scores with DEGs of poorly differentiated HCC. (D) Venn diagram of DEGs between PD HCC tumor tissues and MD\&WD tumor tissues, DEGs of PD HCC, DEGs of MD HCC, and DEGs of WD HCC. 
Table 5: 4 DEGs specific for poorly differentiated HCC

\begin{tabular}{|c|c|c|c|c|c|c|c|c|c|c|c|c|c|c|c|c|c|c|c|c|}
\hline $\begin{array}{c}\text { Entrez } \\
\text { ID }\end{array}$ & $\begin{array}{c}\text { Gene } \\
\text { Symbol }\end{array}$ & N1 & N2 & N3 & N4 & N5 & N6 & N7 & N8 & N9 & T1 & $\mathbf{T 2}$ & T3 & T4 & T5 & T6 & T7 & T8 & T9 & $\begin{array}{c}t \text { test } \\
p \text { value }\end{array}$ \\
\hline 4857 & NOVA1 & 0.45 & 0.92 & 0.60 & 0.46 & 0.33 & 0.60 & 0.34 & 0.34 & 0.68 & 8.90 & 4.66 & 6.21 & 0.53 & 0.54 & 2.34 & 0.93 & 0.14 & 0.19 & $3.92 \mathrm{E}-022$ \\
\hline 286053 & NSMCE2 & 7.21 & 11.26 & 12.07 & 10.67 & 7.07 & 14.89 & 10.64 & 14.13 & 7.46 & 49.75 & 80.27 & 61.78 & 13.90 & 19.52 & 17.62 & 16.57 & 28.10 & 10.60 & $2.74 \mathrm{E}-02$ \\
\hline 9897 & KIAA0196 & 11.23 & 9.64 & 12.62 & 7.93 & 9.70 & 11.73 & 7.95 & 13.44 & 7.68 & 29.40 & 34.53 & 27.14 & 10.02 & 5.18 & 10.03 & 11.86 & 14.91 & 6.73 & $6.78 \mathrm{E}-03$ \\
\hline 55039 & AQP9 & 333.45 & 217.87 & 178.65 & 419.54 & 364.99 & 429.47 & 445.80 & 385.51 & 257.32 & 25.06 & 15.89 & 19.74 & 174.82 & 215.45 & 188.60 & 152.81 & 199.10 & 232.73 & $1.32 \mathrm{E}-03$ \\
\hline
\end{tabular}

Note: N1, N2, N3 and T1, T2, T3 represent adjacent non-tumor tissue and tumor tissue of P1, P2, P3 with poorly differentiated HCC, respectively. N4, N5, N6 and T4, T5, T6 represent adjacent non-tumor tissue and tumor tissue of M1, M2, M3 with moderately differentiated HCC, respectively. N7, N8, N9 and T7, T8, T9 represent adjacent non-tumor tissue and tumor tissue of W1, W2, W3 with well differentiated HCC, respectively. $p$ value refers to T1, T2, T3 vs N1, N2, N3, N4, N5, N6, N7, N8, N9, T4, T5, T6, T7, T8, T9 by $t$ test.

\section{MATERIALS AND METHODS}

\section{Ethics statement}

Our study design was approved by the Ethics Committee of the Fujian Provincial Hospital. Written informed consent was obtained from all subjects.

\section{Subjects}

47 subjects were diagnosed as primary $\mathrm{HCC}$ in the Fujian Provincial Hospital (Table 1), of which 33 subjects were present with cirrhosis on the non-neoplastic

\section{A}

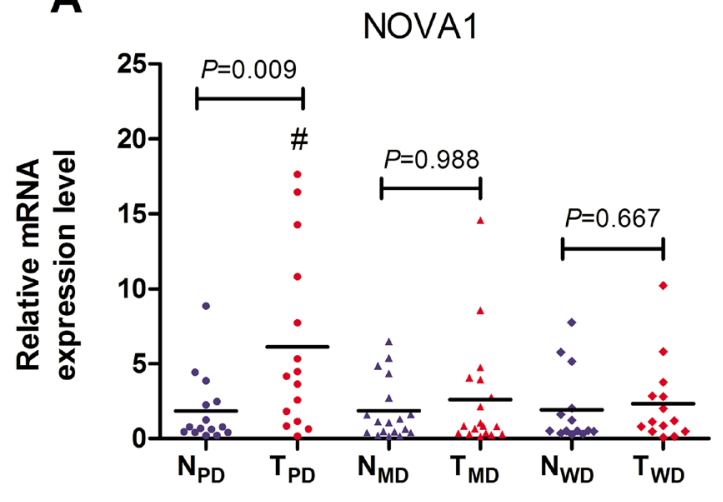

C

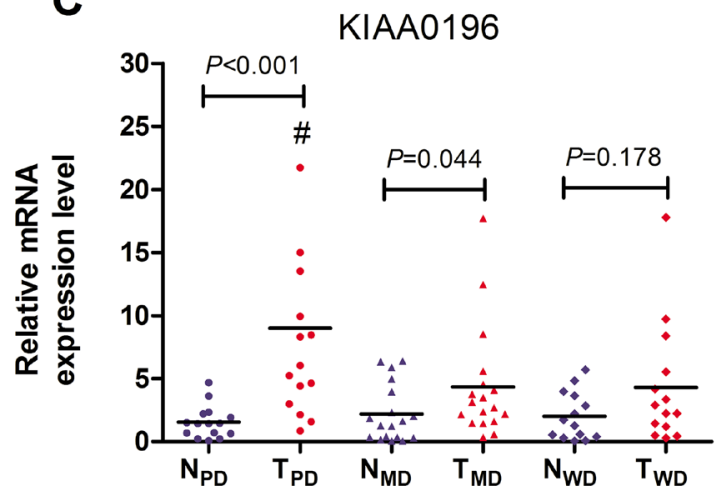

background, including 29 subjects with hepatitis B virus (HBV), 1 subjects with hepatitis $\mathrm{C}$ virus (HCV) and 3 subjects with NBNC. HBV related tumors were defined according to the presence of HB surface antigen (HBsAg) in serum, and $\mathrm{HCV}$ related tumors were according to the presence of antibody to $\mathrm{HCV}$ (HCVAb) in serum. NBNC tumor was defined according to the absence of both HBsAg and HCVAb in serum. Primary tumor and adjacent non-tumorous samples were obtained from all patients who underwent surgical tumor resection. All samples were frozen immediately at $-80^{\circ} \mathrm{C}$ until RNA extraction. Total RNA was isolated by using RecoverAll ${ }^{\mathrm{TM}}$ Total Nucleic Acid Isolation Kit (Life Technologies, Carlsbad, CA,

\section{B}

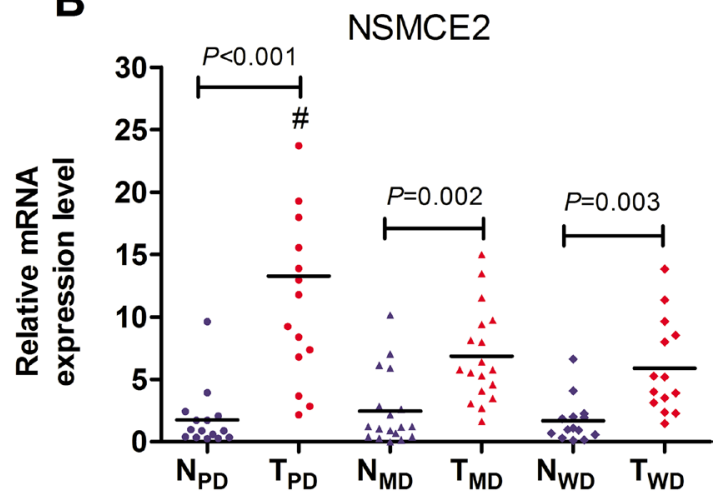

D

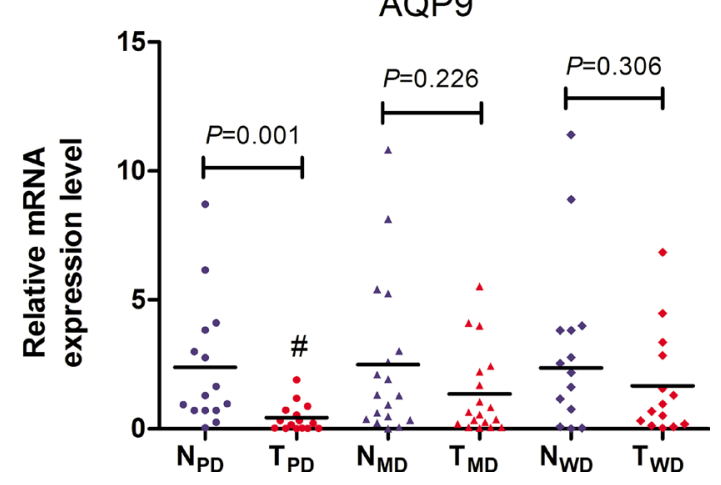

Figure 3: RT-PCR validation of 4 DEGs specific for poorly differentiated HCC. GAPDH mRNA was used as an internal control. Expression data were obtained as $2^{-\triangle \Delta C T}$ relative to adjacent non-tumor tissue values. $\mathrm{N}_{\mathrm{PD}}$ and $\mathrm{T}_{\mathrm{PD}}$ represented matched adjacent non-tumor tissue specimens $(n=15)$ and poorly differentiated HCC tissue specimens $(n=15)$ respectively. $\mathrm{N}_{\mathrm{MD}}$ and $\mathrm{T}_{\mathrm{MD}}$ represented matched adjacent non-tumor tissue specimens $(n=18)$ and moderately differentiated HCC tissue specimens $(n=18)$ respectively. $\mathrm{N}_{\mathrm{wD}}$ and $\mathrm{T}_{\mathrm{WD}}$ represented matched adjacent non-tumor tissue specimens $(n=14)$ and well differentiated HCC tissue specimens $(\mathrm{n}=14)$ respectively. (A) NOVA1; (B) NSMCE2; (C) KIAA0196; (D) AQP9. ${ }^{*} P<0.05$ vs $\mathrm{T}_{\mathrm{MD}}$ and $\mathrm{T}_{\mathrm{WD}}$. 
Table 6: Primers used in this study

\begin{tabular}{|c|c|c|}
\hline Gene & Primers $\left(5^{\prime}-3^{\prime}\right)$ & Length (bp) \\
\hline \multirow[t]{2}{*}{ NOVA1 } & GACCAATACGGGCGAAGACG & 295 \\
\hline & CTGGGGTTGTAGAATGCTGACTG & \\
\hline \multirow[t]{2}{*}{ NSMCE2 } & AGACCAACTTCACCTGCCCC & 131 \\
\hline & CTTTTTCTTCCGCTTTTGCCTG & \\
\hline \multirow[t]{2}{*}{ KIAA0196 } & GAGGGAGGGGTGGAAACTGG & 208 \\
\hline & ATTGTGAGGCGGACCGACTAC & \\
\hline \multirow[t]{2}{*}{ AQP9 } & TGGAGGGGTCATCACTATCAAT & 226 \\
\hline & CATAAGTCCATCATAGTAAATGCCAAA & \\
\hline
\end{tabular}

USA). Integrity of RNA was assessed by Agilent 2100 bioanalyzer (Agilent, Santa Clara, CA, USA). RNA from nine samples was subjected to sequencing and all samples were used in the validation experiments.

\section{Transcriptome sequencing}

Sequencing libraries were prepared by using TruSeq RNA Sample Prep Kit (Illumina, San Diego, CA, USA) according to standard protocols. Briefly, total RNA was firstly randomly fragmented and poly-A-selected. Secondly, the RNA fragments were reverse transcribed to cDNA, end-repaired and ligated with adapters. The libraries then underwent size selection, PCR and purification. The quality of libraries was assessed by using Bioanalyzer 2100 (Agilent, Santa Clara, CA, USA). Sequencing was then performed on an Illumina HiSeq2500 sequencer with 125 bp pair-end reads.

\section{Reads processing}

Raw sequencing reads were firstly filtered for adapters and ribosomal RNA. Reads containing five or more low quality (quality score $<20$ ) bases were also removed. The remained high-quality reads were then aligned to human genome (hg19) by using Tophat [21]. The mapped reads were then subjected to alignment against the human transcriptome (Ensembl, GRCh37.73). Gene expression level measured by FPKM (fragments per kilobase per million) was calculated by Cufflinks [22].

\section{Differentially expressed genes (DEGs) analysis}

For each differentiated HCC group, DEGs between the tumor and matched non-tumorous tissues were identified with pair-wise $t$ test and the significant threshold was set as adjusted $p$-value of less than 0.05 and $\mid \log _{2}$ (fold change, FC) $\mid>=1$. Enrichr was used to do functional enrichment analysis like Gene Ontology (GO) and KEGG pathway [7]. The significant threshold for enrichment was set as $p<0.1$. In addition, the list of up-regulated genes and down-regulated was uploaded into lincscloud [8] to find perturbations which can reverse the cancer condition.
Using similar methods ( $t$ test instead of paired $t$ test), DEGs were identified and analyzed between tumor tissues of PD HCC and those of MD\&WD HCC.

\section{DEGs specific for poorly differentiated HCC validated by RT-PCR}

DEGs specific for poorly differentiated HCC (Compared with 3 matched adjacent non-tumor tissue of poorly differentiated $\mathrm{HCC}, \mathrm{P}<0.05, \mid \log _{2}$ (fold change, FC) $\mid>=1$; Compared with all adjacent non-tumor tissue, 3 moderately differentiated tissue and 3 well differentiated tissue, $\mathrm{P}<0.05, \mid \log _{2}$ (fold change, $\mathrm{FC}$ ) $\mid>=1$ ) were subjected to validation using RT-PCR. The validation cohort included 15 poorly differentiated HCC, 18 moderately differentiated HCC and 14 well differentiated HCC (Table 1). For the RT-PCR reactions, total RNA was converted to cDNA with random hexamer primers using the High-Capacity cDNA Reverse Transcription kit (Applied Biosystems, Foster City, CA, USA). Realtime PCR was performed with SYBR Green I (Applied Biosystems, United States) on ABI 7300 (Applied Biosystems). The primers used were described in Table 6.

\section{Statistical analysis}

$T$-test was used to compare continuous measurement data with a normal distribution between two groups. Mann-Whitney $U$ test was used to evaluate continuous data with a non-normal distribution. Statistical analyses were performed with the SPSS13.0 software (SPSS, United States). $P<0.05$ was considered statistically significant.

\section{Abbreviations}

HCC, hepatocellular carcinoma; PD, poorly differentiated; $\mathrm{MD}$, moderately differentiated; $\mathrm{WD}$, well differentiated; DEGs, differentially expressed genes; GO, Gene Ontology; KEGG, Kyoto Encyclopedia of Genes and Genomes; PI3K, phosphatidylinositol 3-kinase; Akt, protein kinase $\mathrm{B}$; mTOR, mammalian target of rapamycin; MAPK, mitogen activated kinase-like protein; 
MYC, Myc proto-oncogene protein; CDKN1B, cyclin dependent kinase inhibitor 1B; FPKM, fragments per kilobase per million; HBV, Hepatitis B virus; $\mathrm{HBsAg}$, HB surface antigen; $\mathrm{HCV}$, Hepatitis $\mathrm{C}$ virus; NBNC tumor, non-B non-C tumor; NOVA1, NOVA alternative splicing regulator 1; NSMCE2, NSE2/MMS21 homolog, SMC5SMC6 complex SUMO ligase; AQP9, aquaporin 9.

\section{Authors' contributions}

YH: guarantor of integrity of the entire study, study concepts, study design, definition of intellectual content, literature research, experimental studies, data acquisition, data analysis, statistical analysis, manuscript preparation, manuscript editing, manuscript review; JP: guarantor of integrity of the entire study, study concepts, study design, definition of intellectual content, literature research, experimental studies, data acquisition, data analysis, statistical analysis, manuscript preparation; DC: guarantor of integrity of the entire study, study concepts, study design, definition of intellectual content, literature research, experimental studies, data acquisition, data analysis, statistical analysis; JZ: experimental studies, data acquisition, data analysis, statistical analysis; FQ: experimental studies, data acquisition, data analysis; FL: experimental studies, data acquisition, data analysis; YW: data analysis, statistical analysis, manuscript preparation; Wenbing Wu experimental studies, data acquisition; $\mathrm{XH}$ : data analysis, statistical analysis; JQ: guarantor of integrity of the entire study, study concepts, study design, definition of intellectual content, literature research, manuscript review. YH and JP contributed equally to this study. All authors read and approved the final manuscript.

\section{ACKNOWLEDGMENTS}

We thank AIC biotechnology for their support in transcriptome sequencing and analysis.

\section{CONFLICTS OF INTEREST}

All authors declare that they have no any conflicts of interests.

\section{FUNDING}

This study was supported by the Middle-Young Age Backbone Talent Cultivation Program of Fujian Health System, No. 2013-ZQN-JC-2; and Key Projects of Science and Technology Plan of Fujian Province, No. 2014Y0009.

\section{REFERENCES}

1. Siegel RL, Miller KD, Jemal A. Cancer statistics, 2015. CA Cancer J Clin. 2015; 65:5-29.
2. Oishi K, Itamoto T, Amano H, Fukuda S, Ohdan H, Tashiro H, Shimamoto F, Asahara T. Clinicopathologic features of poorly differentiated hepatocellular carcinoma. J Surg Oncol. 2007; 95:311-316.

3. Arii S, Yamaoka Y, Futagawa S, Inoue K, Kobayashi K, Kojiro M, Makuuchi M, Nakamura Y, Okita K, Yamada R. Results of surgical and nonsurgical treatment for smallsized hepatocellular carcinomas: a retrospective and nationwide survey in Japan. The Liver Cancer Study Group of Japan. Hepatology. 2000; 32:1224-1229.

4. Simon EP, Freije CA, Farber BA, Lalazar G, Darcy DG, Honeyman JN, Chiaroni-Clarke R, Dill BD, Molina H, Bhanot UK, La Quaglia MP, Rosenberg BR, Simon SM. Transcriptomic characterization of fibrolamellar hepatocellular carcinoma. Proc Natl Acad Sci U S A. 2015; 112: E5916-5925.

5. Lin KT, Shann YJ, Chau GY, Hsu CN, Huang CY. Identification of latent biomarkers in hepatocellular carcinoma by ultra-deep whole-transcriptome sequencing. Oncogene. 2014; 33:4786-4794.

6. Ho DW, Kai AK, Ng IO. TCGA whole-transcriptome sequencing data reveals significantly dysregulated genes and signaling pathways in hepatocellular carcinoma. Front Med. 2015; 9:322-330.

7. Kuleshov MV, Jones MR, Rouillard AD, Fernandez NF, Duan Q, Wang Z, Koplev S, Jenkins SL, Jagodnik KM, Lachmann A, McDermott MG, Monteiro CD, Gundersen GW, et al. Enrichr: a comprehensive gene set enrichment analysis web server 2016 update. Nucleic Acids Res. 2016; 44: W90-97.

8. Duan Q, Flynn C, Niepel M, Hafner M, Muhlich JL, Fernandez NF, Rouillard AD, Tan CM, Chen EY, Golub TR, Sorger PK, Subramanian A, Ma'ayan A. LINCS Canvas Browser: interactive web app to query, browse and interrogate LINCS L1000 gene expression signatures. Nucleic Acids Res. 2014; 42: W449-460.

9. Zhang L, Guo Y, Li B, Qu J, Zang C, Li F, Wang Y, Pang H, Li S, Liu Q. Identification of biomarkers for hepatocellular carcinoma using network-based bioinformatics methods. Eur J Med Res. 2013; 18: 35.

10. Tsai TH, Song E, Zhu R, Di Poto C, Wang M, Luo Y, Varghese RS, Tadesse MG, Ziada DH, Desai CS, Shetty K, Mechref Y, Ressom HW. LC-MS/MS-based serum proteomics for identification of candidate biomarkers for hepatocellular carcinoma. Proteomics. 2015; 15:2369-2381.

11. Babeu JP, Boudreau F. Hepatocyte nuclear factor 4-alpha involvement in liver and intestinal inflammatory networks. World J Gastroenterol. 2014; 20:22-30.

12. Gedaly R, Angulo P, Hundley J, Daily MF, Chen C, Koch A, Evers BM. PI-103 and sorafenib inhibit hepatocellular carcinoma cell proliferation by blocking Ras/Raf/MAPK, PI3K/ AKT/mTOR pathways. Anticancer Res. 2010; 30:4951-4958.

13. Wilson JM, Kunnimalaiyaan S, Gamblin TC, Kunnimalaiyaan M. MK2206 inhibits hepatocellular 
carcinoma cellular proliferation via induction of apoptosis and cell cycle arrest. J Surg Res. 2014; 191:280-285.

14. Sunaga N, Shames DS, Girard L, Peyton M, Larsen JE, Imai H, Soh J, Sato M, Yanagitani N, Kaira K, Xie Y, Gazdar AF, Mori M, et al. Knockdown of oncogenic KRAS in non-small cell lung cancers suppresses tumor growth and sensitizes tumor cells to targeted therapy. Mol Cancer Ther. 2011; 10:336-346.

15. Lim S, Kaldis P. Cdks, cyclins and CKIs: roles beyond cell cycle regulation. Development. 2013; 140:3079-3093.

16. Zhang YA, Zhu JM, Yin J, Tang WQ, Guo YM, Shen XZ, Liu TT. High expression of neuro-oncological ventral antigen 1 correlates with poor prognosis in hepatocellular carcinoma. PLoS One. 2014; 9: e90955.

17. Ni HJ, Chang YN, Kao PH, Chai SP, Hsieh YH, Wang DH, Fong JC. Depletion of SUMO ligase hMMS21 impairs G1 to $\mathrm{S}$ transition in MCF-7 breast cancer cells. Biochim Biophys Acta. 2012; 1820:1893-1900.

18. Wang F, Zhang L, Zhang GL, Wang ZB, Cui XS, Kim NH, Sun SC. WASH complex regulates Arp2/3 complex for actin-based polar body extrusion in mouse oocytes. Sci Rep. 2014; 4: 5596.
19. Porkka KP, Tammela TL, Vessella RL, Visakorpi T. RAD21 and KIAA0196 at 8q24 are amplified and overexpressed in prostate cancer. Genes Chromosomes Cancer. 2004; 39:1-10.

20. Zhang WG, Li CF, Liu M, Chen XF, Shuai K, Kong X, Lv L, Mei ZC. Aquaporin 9 is down-regulated in hepatocellular carcinoma and its over-expression suppresses hepatoma cell invasion through inhibiting epithelial-to-mesenchymal transition. Cancer Lett. 2016; 378:111-119.

21. Trapnell C, Pachter L, Salzberg SL. TopHat: discovering splice junctions with RNA-Seq. Bioinformatics. 2009; 25:1105-1111.

22. Trapnell C, Williams BA, Pertea G, Mortazavi A, Kwan G, van Baren MJ, Salzberg SL, Wold BJ, Pachter L. Transcript assembly and quantification by RNA-Seq reveals unannotated transcripts and isoform switching during cell differentiation. Nat Biotechnol. 2010; 28:511-515. 